\title{
Calculation of Chemical Detonation Waves with Hydrodynamics and $A$ Thermochemical Equation of State
}

\author{
W. M. Howard, L. E. Fried, P. C. Souers, P. A. Vitello
}

This article was submitted to $12^{\text {th }}$ American Physical Society Topical Conference, Atlanta, GA., June 24-29, 2001

U.S. Department of Energy

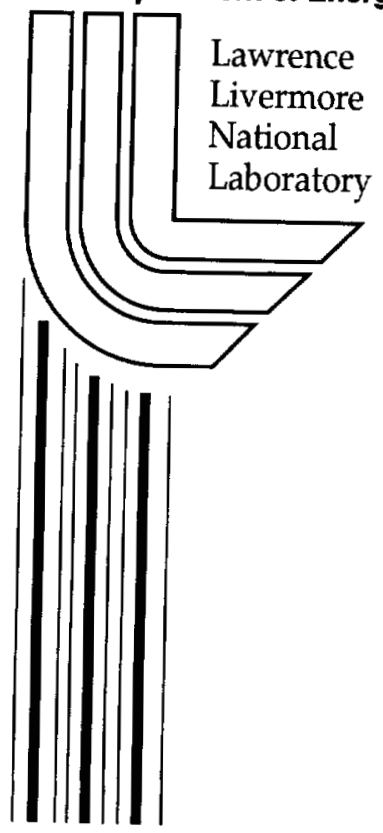

August 1, 2001 


\section{DISCLAIMER}

This document was prepared as an account of work sponsored by an agency of the United States Government. Neither the United States Government nor the University of California nor any of their employees, makes any warranty, express or implied, or assumes any legal liability or responsibility for the accuracy, completeness, or usefulness of any information, apparatus, product, or process disclosed, or represents that its use would not infringe privately owned rights. Reference herein to any specific commercial product, process, or service by trade name, trademark, manufacturer, or otherwise, does not necessarily constitute or imply its endorsement, recommendation, or favoring by the United States Government or the University of California. The views and opinions of authors expressed herein do not necessarily state or reflect those of the United States Government or the University of California, and shall not be used for advertising or product endorsement purposes.

This is a preprint of a paper intended for publication in a journal or proceedings. Since changes may be made before publication, this preprint is made available with the understanding that it will not be cited or reproduced without the permission of the author.

This work was performed under the auspices of the United States Department of Energy by the University of California, Lawrence Livermore National Laboratory under contract No. W-7405-Eng-48.

This report has been reproduced directly from the best available copy.

Available electronically at http://www.doc.gov/bridge

Available for a processing fee to U.S. Department of Energy

And its contractors in paper from

U.S. Department of Energy

Office of Scientific and Technical Information

P.O. Box 62

Oak Ridge, TN 37831-0062

Telephone: (865) 576-8401

Facsimile: (865) 576-5728

E-mail: reports@adonis.osti.gov

Available for the sale to the public from

U.S. Department of Commerce

National Technical Information Service

5285 Port Royal Road

Springfield, VA 22161

Telephone: (800) 553-6847

Facsimile: (703) 605-6900

E-mail: orders@ntis.fedworld.gov

Online ordering: http://www.ntis.gov/ordering.htm

\section{OR}

Lawrence Livermore National Laboratory

Technical Information Department's Digital Library

http://www.llnl.gov/tid/Library.html 


\title{
CALCULATION OF CHEMICAL DETONATION WAVES WITH HYDRODYNAMICS AND A THERMOCHEMICAL EQUATION OF STATE
}

\author{
W. M. Howard, L. E. Fried, P. C. Souers and P. A. Vitello \\ Lawrence Livermore National Laboratory, 7000 East Avenue L-282, Livermore, CA 94550
}

\begin{abstract}
We model detonation waves for solid explosives, using 2-D Arbitrary Lagrange Eulerian (ALE) hydrodynamics, with an equation of state (EOS) based on thermochemical equilibrium, coupled with simple kinetic rate laws for a few reactants. The EOS for the product species is based on either a BKWC EOS or on an exponential-6 potential model, whose parameters are fitted to a wide range of shock Hugoniot and static compression data. We show some results for the non ideal explosive, urea nitrate. Such a model is a powerful tool for studying such processes as initiation, detonation wave propagation and detonation wave propagation as a function of cylindrical radius.
\end{abstract}

\section{INTRODUCTION}

We calculate detonation waves for confined and non-confined explosives with a 2-D Arbitrary Lagrange Eulerian (ALE) hydrodynamics code that includes a detailed thermochemical equation of state (EOS) and rate law kinetics. An earlier version of this work has been reported in ref [1]. We link an inline thermochemical code (CHEETAH[2]) with a 2D ALE hydrodynamics code to provide the EOS. The EOS allows for products to be in thermochemical equilibrium with an arbitrary number of reactants coupled via arbitrary rate laws. CHEETAH calculates the chemical composition of the reacting high explosive gases, and then predicts the EOS of the gases using a high pressure fluid EOS. The transformation of the solid high explosives into a reacting fluid of small product molecules is based on simplified chemical kinetic schemes, which are determined from measured detonation velocities as a function of size.

The EOS for products in our code can be based on a BKWC model [3] or an exponential-6 potential [4] for supercritial fluids, with a Murnaghan form [5] for solids and liquids. The BKWC co-volumes are chosen to replicate a wide range of detonation velocity data for $\mathrm{C}, \mathrm{N}, \mathrm{O}, \mathrm{H}, \mathrm{F}$ explosives. For the exponential-6-based EOS, the parameters are chosen to reproduce the shock hugoniot and static compression data for a wide range of supercritical fluids [2.4,6]. This is an accurate and efficient complete equation of state of the exponential-6 fluid based on HMSA integral equation theory and Monte Carlo calculations. However, for this study, we have chosen to use BKWC.

For the purposes of this study, we are interested in so called "non ideal" high explosives, because they reveal interesting hydrodynamic and kinetic effects. We define non-ideal explosives as those with a finite (more than one $\mathrm{mm}$ ) reaction zone. Non-ideal explosives are often poorly modeled by Chapman-Jouget (CJ) or Zeldovich-Von NeumannDoring (ZND) theory, where it is assumed that thermodynamic equilibrium of the detonation products is reached instantaneously. For example, it is found experimentally that the detonation velocity of non-ideal explosives can vary sharply from the $\mathrm{CJ}$ value and depend on the charge radius. In addition, the detonation wave front can exhibit significant curvature, because the reactants are consumed on a time scale comparable with that of the passage of the detonation wave.

Therefore, one requires the interaction of chemical kinetics with the detonation wave in order 
to have an acceptable representation of detonation in non ideal explosives. Wood and Kirkwood [7] (WK) proposed a two dimensional steady state kinetic detonation theory that solves many of the limitations of CJ (or ZND) theory. WK considered a cylindrical charge of infinite length. They solved the hydrodynamic Euler equations in the steady state limit along the central streamline of the cylinder. Radial expansion was treated as a source term in the 1-D flow along the streamline.

Earlier, we reported [8] on implementing WK theory into the thermochemical CHEETAH code. One problem with WK theory, as mentioned above, is that the rate of radial expansion along the center streamline, which can also depends on the charge size, must be specified. In addition, one must also specify the kinetic rate laws for the decomposition of the high explosive, for which there is little experimental or theoretical knowledge. Using the ALE hydrodynamics, coupled with the in-line CHEETAH code, can help us gain information on these parameters. For example, the kinetic rate laws can be varied to fit the experimental detonation data.

We can then take the kinetic rate laws and rate of radial expansion extracted from the hydrodynamic calculation as input into the WKCHEETAH calculation. For the case of urea nitrate that we describe in this study, we find that this procedure works very well. When we take the rate of radial expansion and the kinetic rate laws from the ALE calculation as input into the WK-CHEETAH model, it reproduces the ALE calculations. That is, the detonation velocity, peak pressure and density are reasonably matched between the two calculations.

An additional advantage of using the ALE hydrodynamics code is that we can also make use of strength and melt models for metals [9]. This allows for the study of the interaction of detonation waves with metals. For example, we can compare the cylinder wall expansion data with our calculations to validate material strength models and detonation energy release models. In our calculations, we are also able to resolve the Von Neumann pressure spike and reaction zone and study their dependence on the kinetic rate laws and the EOS.

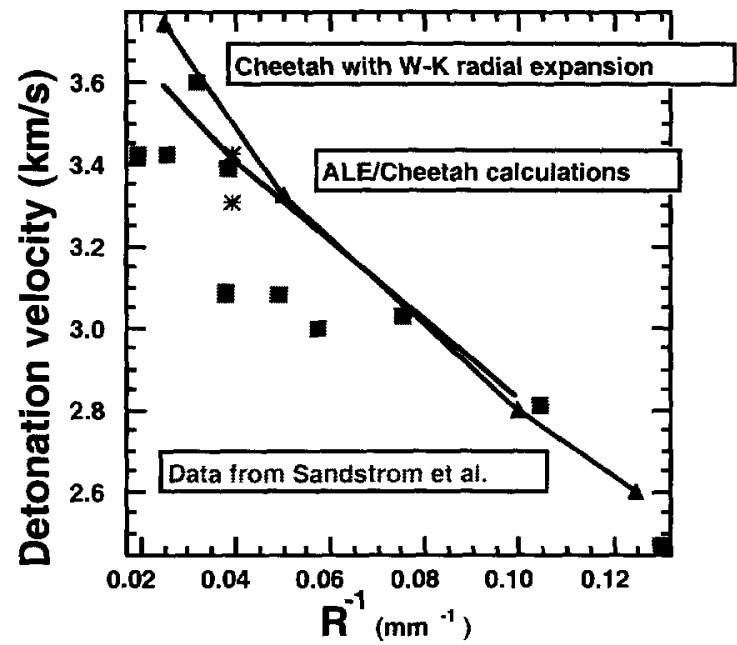

Figure 1. Detonation velocity as a function of inverse cylinder size for urea nitrate. The red squares are data for unconfined urea nitrate[10]. The blue triangles are results from the ALE simulations, while the black triangles are results from WKCHEETAH calculations. For this case, the ALE and WK calculations agree quite well with one another.

\section{RESULTS}

We have chosen to study the detonation of urea nitrate $\left(\mathrm{CH}_{4} \mathrm{~N}_{2} \mathrm{O}-\mathrm{HNO}_{3}\right)$, because its detonation properties have been well studied. There is experimental detonation velocity data for both confined and unconfined cylinders, for a wide range of cylinder sizes [10]. In addition, there is also a detonation wave curvature measurement.

For urea nitrate we take the heat of formation to be

Hof $=-563 \mathrm{~kJ} / \mathrm{mole}$,

and for the Murnaghan parameters for the unreacted urea nitrate, we take

$\mathrm{B}_{\mathrm{o}}=8.17 \mathrm{GPa}$ and $\mathrm{B}_{\mathrm{o}}=7.0$.

The unconfined urea nitrate experiments correspond to an initial density, $\rho_{0}=0.69 \mathrm{~g} / \mathrm{cm}^{3}$.

The results of our calculations are summarized in Figure 1. The rate law for the decomposition of urea nitrate that best represents the experimental data is given by: 
$\frac{d \lambda}{d t}=0.7 \cdot P(G P a) \mu \sec ^{-1}$,

where $\lambda$ represents the amount of unburned reactant normalized to vary between 0 (all unburned) and 1 (all burned). Since all reaction products are assumed to be in thermochemical equilibrium, the exact decomposition pathway is unimportant. We have chosen to use a very simple P-dependent kinetic rate law for the decomposition of the urea nitrate. We find that this choice, while simpler than most reactive flow rate laws for high explosive initiation, is adequate to model steady-state detonation over the range of diameters provided here.

The red squares represent data for unconfined urea-nitrate, while the stars represent data for a confined urea-nitrate explosion. The black line represents the calculations with ALE and the red line represents calculations with WK-CHEETAH.

For the WK-CHEETAH calculations we have used the same rate law as in the ALE calculations. The WK-CHEETAH calculation requires the spatial derivative of the radial velocity along the centerline of the detonation flow. In WK theory, this is represented by:

$\omega_{r}=(D-u(t=0)) / R_{c}$,

where $R_{c}$ is the radius of curvature taken from the ALE calculations.

Figure 2 shows the calculated detonation wave for unconfined urea-nitrate. For the hydrodynamic calculations we have used a zonal resolution of between 20 and 50 zone $/ \mathrm{cm}$. Notice that the curvature front has some irregularities on the front surface. Figure 3 shows the calculated wave front curvature for a confined urea-nitrate detonation. The cylinder metal is a $0.26 \mathrm{~cm}$-thick copper tube.

The WK-CHEETAH calculations predict that the reaction zone length is about $5 \mathrm{~mm}$ and that most of the urea nitrate is consumed within the reaction zone. The calculated Von Neumann spike is about 60 kbars with a width of about $1 \mathrm{~mm}$. The calculated pressure and density spatial profiles agree reasonably well with the ALE calculations, with the WK calculations showing a somewhat more rapid fall off with distance behind the detonation wave.

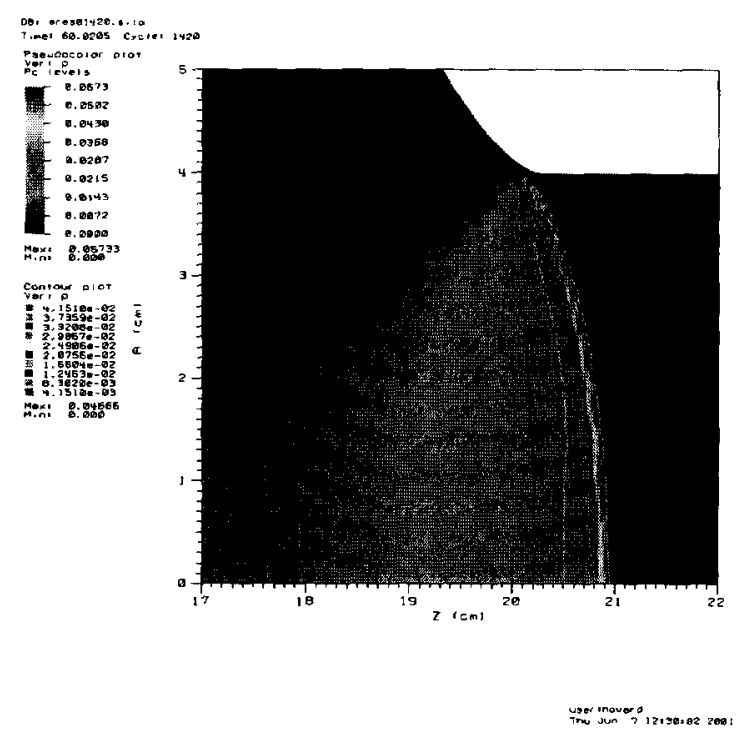

Figure 2. Pressure profiles for the detonation of $40 \mathrm{~mm}$ radius unconfined urea nitrate. Notice the structure in the detonation wave.

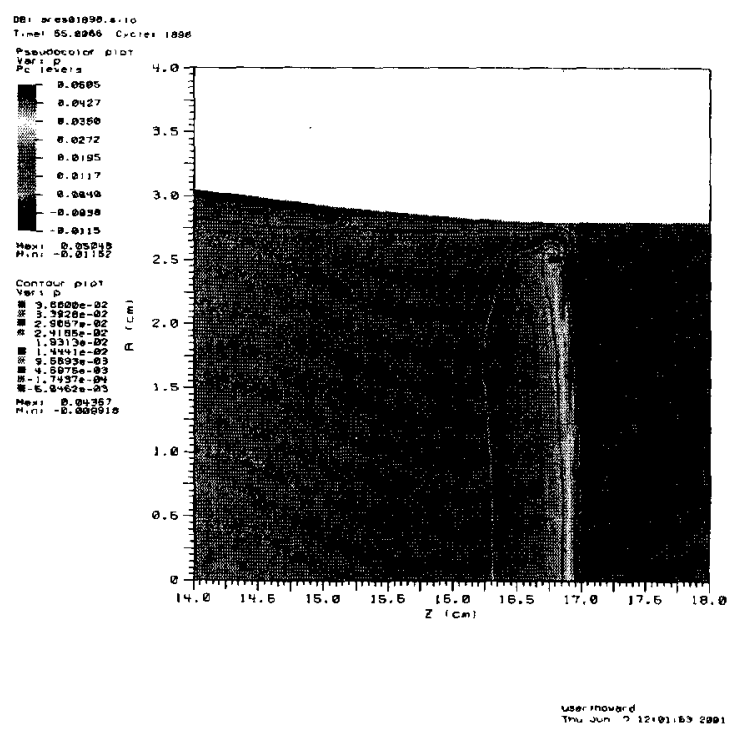

Figure 3. Pressure profiles for the detonation of $25.4 \mathrm{~mm}$ radius confined urea nitrate. 


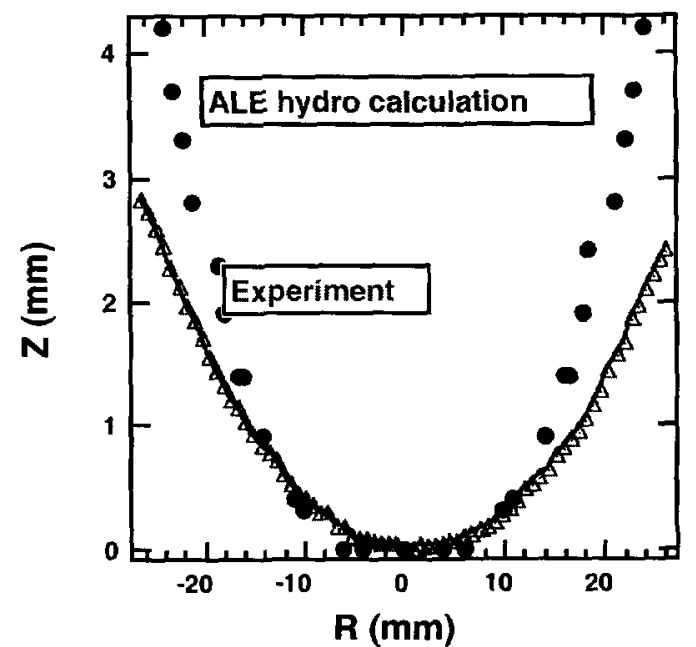

Figure 4. The detonation wave-front curvature for unconfined $26.5 \mathrm{~mm}$ radius urea-nitrate. The red line is the measurements [10], while the blue dots are from our ALE calculation.

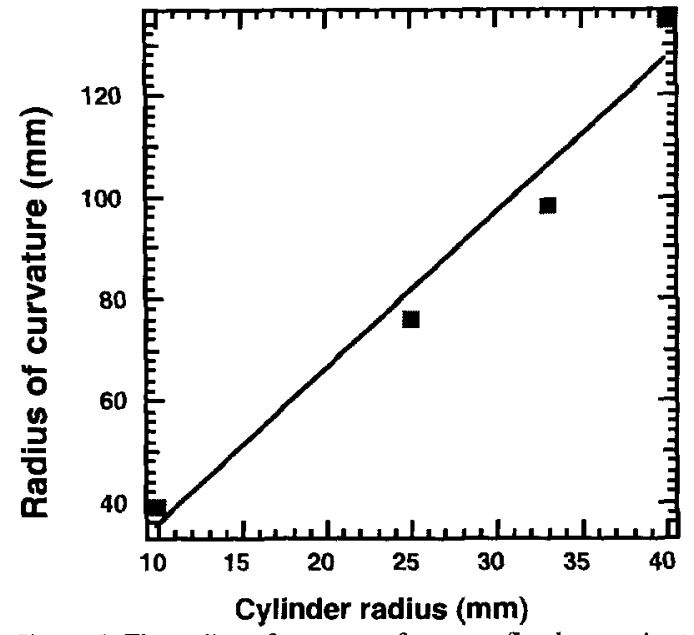

Figure 5. The radius of curvature for unconfined urea-nitrate as a function of charge radius, as calculated with ALE. This result can be used by WK-CHEETAH to calculate the detonation velocity as a function of charge radius.

Figure 5 shows the calculated radius of curvature at $\mathrm{R}=0$ (center line) for unconfined urea-nitrate, as a function of charge radius. The curvature was assumed to be quadratic. When the calculated radii of curvature is used in the WK Cheetah calculations, we obtain the detonation velocities given in Figure 1
We applied both our WK-CHEETAH model and our ALE model to the calculation of the detonation of urea nitrate. We find that both models reproduce the experimental data reasonably well with a simple kinetic rate law. If we take the radius of curvature as a function of charge radius from the ALE calculations and use them in the WK model to calculate the rate of radial divergence, then the WK model can replicate the ALE results.

\section{ACKNOWLEDGEMENTS}

This work was performed under the auspices of the United States Department of Energy by the Lawrence Livermore National Laboratory under Contract No. W-7405-ENG-48

\section{REFERENCES}

1. Fried, L. E., Murphy, M. J., Souers, P. C., Wu, B. J., Anderson, S. R., McGuire, E. M. and Maiden, D. E. "Detonation Modeling with an In-Line Thermochemical Equation of State", Proceeding $1^{\text {th }}$ International Detonation Symposium, Snowmass, Colorado, August, 1998.

2. Fried, L. E., Howard, W. M. and P. C. Souers, Cheetah 3.0, Lawrence Livermore National Laboratory, June, 2001.

3. Fried, L. E. and Souers, P. C., "BKWC: An Emperical BKW Parameterization Based on Cylinder Test Data", Propellants, Explosives and Pyrotechnics, 21, 215, 1996.

4. Fried, L. E. and Howard, W. M. , "An Accurate Equation of State for the Exponential-6 Fluid Applied to Dense Supercritical Nitrogen", J. Chem. Phys., 109, 7338 (1998).

5. Murnaghan, F. D., Proc. Natl. Acad. Sci. (USA), 30, 244, 1944.

6. Fried, L. E. and Howard, W. M. "The Equation of State of Supercritical HF, HCL, and Reactive Supercritical Mixtures containing the Elements $\mathrm{H}, \mathrm{C}, \mathrm{F}$, and $\mathrm{Cl}^{\prime \prime}, J$. Chem. Phys., 110, 7338, 1999.

7. Wood, W. W. and Kirkwood, J. G., "Diameter Effect in Condensed Explosives", J. Chem. Phys., 22, 1920, 1954.

8. Howard, W. M., Fried, L. E. and Souers, P. C., "Kinetic Modeling of Non Ideal Explosives with Cheetah", Proceedings of $11^{\text {th }}$ International Detonation Symposium, Snowmass, Colorado, August, 1998.

9. Steinberg, D. J. and Guinan, M. W., "A High-Strain-Rate Constitutive Model for Metals", UCRL-80465, Lawrence Livremore National Laboratory, 1978. 10 . Sandstrom, F. W., Abernathy, R. L., Leone, M. G. and Banks, M. L., "Diameter Effect and Detonation Front Curvature of Ideal and Non Ideal Explosives", Shock Compression of Condensed Matter 1999, A.I.P., 825, 1999

\section{CONCLUSIONS}

